\title{
Interaction of Parenting Style of Mothers and Paediatric Diabetes Management
}

\author{
Jolanta Žilinskienė, Linas Šumskas, Dalia Antinienė, Jolita Jonynienė \\ Lithuanian University of Health Science, Kaunas, Lithuania
}

\begin{abstract}
Background. Parent-child relationship and parenting style are very important for the child's mental and physical health. This study was focused on investigating the association between mothers' parenting style (PS) and their children's with type I diabetes (T1DM) disease management. We hypothesized that mothers' PS interact with their children's T1DM outcomes.

Methods. One hundred thirty-one mothers, the main caregivers of their diabetic children, filled in the parenting style and demographic questionnaires. The indicator of diabetes management was Haemoglobin A1c (HbA1c) the main form of glycosylated haemoglobin. PS scales and subscales were associated with glycaemic management indices. Binary logistic regression analysis was applied for the assessment of the association between mothers' PS and their children's with T1DM disease management.

Results. While logistic regression analysis did not demonstrate statistically significant interaction of T1DM management and mothers' PS scales and subscales, cluster analysis showed that in the confrontation with T1DM, the relationships between children and parents were dominated by negative elements of PS: lack of emotional warmth, support, reasoning and especially democratic participation.

Conclusion. Children's T1DM management and their mothers' PS scales and subscales did not demonstrate statistically significant interaction. PS negative elements dominate in mothers' upbringing: lack of emotional warmth, support, reasoning and especially democratic participation.
\end{abstract}

Keywords: type 1 diabetes, parenting skills, parenting style, diabetes management.

\section{INTRODUCTION}

$\mathrm{T}$ lype I diabetes (T1DM) is one of the major chronic diseases prevalent these days (Center for Disease Control and Prevention, 2020). It affects about $5-10$ percent all diabetes patients and it is probably the most common chronic disease in children and adolescents (Wherrett et al., 2018).

T1DM completely changes a person's life, so it is often referred to not as a chronic illness but as a forced lifestyle. T1DM requires a continuous, sufficiently complex healthcare regimen: daily insulin injections, blood glucose control, monitoring of sugar intake, healthy eating, and physical activity (Silverstein et al. 2005). Strict adherence to these instructions is essential because keeping blood sugar as close to normal as possible from the onset of the disease helps to prevent complications such as blindness, ischemic heart disease, kidney disease, leg gangrene and stroke in the short or permanent way (Martin, Albers, Pop-Busui, \& DCCT/EDIC Research Group 2014), Nathan \& DCCT/EDIC Research Group, 2014; Umanath \& Lewis, 2018).

Diabetes affects not only the ill child but also his/her entire family. That is, parents are responsible for the children's ability to manage T1DM performance and the effectiveness of the necessary procedures. Proper management of T1DM requires cooperation, mutual understanding and a warm, supportive relationship between both parents and their child. Thus, this disease completely changes family life both socially and psychologically. As a result, individuals caring for chronic illnesses, especially parents of T1DM affected children, experience anxiety, fear, feelings of uncertainty, and parenting stress. These feelings negatively 
affect parents' relationship with the child, and foster the specific conflict that arises from the inability to agree on disease management tasks. As a result, children and adolescents have poorer adherence to the regime and their health deteriorates (Lewin et al., 2006). Therefore, T1DM often is referred as a "family disease" because family interactions, communication styles, and parental responsibility and role distribution contribute to the T1DM management (Anderson, Ho, Brackett, Finkelstein, \& Laffel, 1997).

In general, the child's social and emotional abilities, attitude to life, value system depend on the parents. Thus, conflicts over diabetes, excessive parental pressure or, vice versa, indifference negatively affect the family's psychological climate, which worsens the relationship between children and parents. As a result, the management of the disease becomes ineffective, various psychological disorders (depression) may develop and the quality of life may deteriorate. There are many articles in the scientific literature about the concept of T1DM, the caused problems, and the psychosocial needs of patients, but there is a lack of a systematic approach to the peculiarities of the relationship between children and parents. This aspect is especially important because it ensures the effectiveness of disease management, avoidance of complications and life satisfaction.

Effective T1DM management requires coordination and cooperation from both parents and children (Palmer et al., 2011). Collaborative communication, emotional support and promotion of independence motivate the child to become autonomous and achieve the set goals, gradually allowing him to be involved in various aspects of T1DM care as his parents continue to monitor the performance of essential tasks (Ivey, Wright, \& Dashiff, 2009).

A number of authors, talking about the relationship between children and parents, mention the parenting style chosen by parents as a very important construct.

Parenting style is a well-researched conceptual categorization of parents' interactions with their children. Using behavioural continuums representing parental responsiveness (warmth, supportiveness) and demandingness (behavioural control), three main styles of parenting behaviours have been identified. Authoritative parenting includes consistent but flexible limits along with high levels of warmth and nurturance. Authoritarian parents exert a high degree of control and value, clear, structured environments and obedience to rules; permissive parents are responsive to children's emotional needs but are not particularly structured or demanding (Baumrind, 1971)

According to Monaghan and colleagues (2012), authoritative parenting not only leads to better T1DM management, reduces parenting stress, but also improves the child's behaviour and dependent disease management, health status, and the family functioning. This is confirmed by Butler and colleagues (2009): a warm, supportive parenting style is important for the health of children with T1DM as it reduces the depressive symptoms of both mothers and their children, promotes selfefficacy. Therefore, the relationships between them are better. An authoritative parenting style is the most effective in maintaining a good relationship with a T1DM affected child, and is opposite to the authoritarian or permissive ones. It allows them to be independent and free to make decisions, but at the same time parents are involved in the care of the disease, collaborating together to make important decisions (Shorer et al., 2011).

Parents who have chosen a mindful parenting style pay a lot of attention to the child: they listen to him or her, accept him or her as he or she is, do not criticize, fully understand their own and the child's emotions, behaviour, feel sorry for themselves and the offspring (Duncan, Coatsworth, \& Greenberg, 2009). Van der Oord and colleagues (2012) note that such parents respond more calmly to negative diabetes-related situations because they behave less automatically. Also, the results of a study by Turpyn and Chaplin (2015) revealed that careful parenting reduces negative parental emotions (e.g., crying, anger) and encourages the sharing of positive reactions (e.g., laughter) as a result of diabetes conflict. Authorative parenting style has been associated not only with better interactions between children and parents, but also with better glycaemic control, quality of life for children (Serkel-Schrama et al., 2016).

According to Jaser and Gray (2010), the stress, anxiety, and depressive symptoms experienced by parents, especially mothers, associated with diabetes, promote parents to be overly involved in the care of the disease. According to Armstrong, Mackey and Streisand (2011), overly intrusive parental behaviour can be very harmful because it prevents adolescents from acquiring appropriate self-management behaviours and causes family conflicts. In a study 
by Gruhn, Lord, and Jaser (2016), all participating mothers reported experiencing stress and anxiety about diabetes, which was significantly associated with an overly involved parenting style, but not with depressive symptoms. Empirical studies allow us to observe statistically significant associations between authoritarian and overly intrusive parenting styles and the symptoms of psychological distress and hopelessness, inferiority observed in children with T1DM.

Parent-child relationships are often characterized by excessive anxiety, strict rules, limitations, criticism, rudeness, and low emotional support, all of which are associated with poorer glycaemic control, disease management, and more frequent depressive symptoms among young people (Cameron et al., 2008). This happens because parents using coercive parenting strategies reduce children's motivation and ability to perform disease care tasks effectively (Landers, Friedrich, Jawad, \& Miller, 2016). Meanwhile adolescents' high quality relationships with their parents (mother and father) were associated with better treatment adherence and metabolic control through less peer orientation. It is likely that high quality adolescentparent relationships may be beneficial to adolescent diabetes management through a healthy balance between peer and parental influence (Drew, Berg, $\&$ Wiebe, 2010).

Thus, critical parenting (criticism, teasing, negativity) negatively affects the quality of parentchild relationships and contributes to poorer T1DM management in all aged children, depressive symptoms in adolescents, and poor self-care (Armstrong, Mackey, \& Streisand, 2011).

The aim of this research paper was to investigate the association between children's T1DM management and mothers' PS. We presupposed that mothers' ability to upbring positively would be related to better children's T1DM management.

\section{METHODS}

Subjects and Study Procedures. The data on children T1DM and Parenting style analysed below were collected in a survey conducted from 2017 till 2019 in Lithuania in the framework of a large study consisting of several stages and with multiple scientific aims. To be involved in the study, participants had to be parents or primary care givers of children with T1DM. Their children had to be from 6 to 12 years old at the time of implication and had to be diagnosed with T1DM for at least 12 months and did not have serious comorbid medical or mental conditions. The parents' places of residence were six major Lithuanian cities. We selected participants from the Lithuanian Diabetes Registry and invited to participate in the study. Purposive sampling was used to form the pool of respondents.

The period of 30-45 minutes was provided as the time frame for filling in the questionnaires. Measures of anonymity and confidentiality were ensured. Parents sealed the provided envelopes with the questionnaires inside after finishing answering. Researchers were instructed about the process of carrying out the survey and how to report the number of participants.

After the completion of the questionnaire survey, the data was checked and exported to the SPSS 23.0 software. The whole analysis was performed using the Complex Samples module of SPSS (version 23.0, Chicago, IL, USA) which adjusts for the complex cluster-stratified sampling method and weighted data; $p<.05$ was considered to be statistically significant.

The final data file, which included information on 131 respondents, mothers of children aged from 6 to 12 year was formed. Thus, our study covered 131 mothers aged from 25 to 56 year. The response rate in the total sample was $89 \%$.

Instrument and Variables. The research instrument consisted of questions about demographic and medical information, metabolic control, and parenting style (PS) scale.

Demographic and medical information. Parents provided family and child's demographic data and child's medical history (e.g., T1DM history and events).

Metabolic control. Hemoglobin A1c (HbAlc; the main form of glycosylated hemoglobin) levels were routinely measured at clinic visits every two three months. HbAlc is an indicator of average blood glucose concentration over the previous three months. The recommended $\mathrm{HbAlc}$ level for children is $<7.5 \%$ (American Diabetes Association, 2018; Chiang et al., 2014). The results of a gHbAlc were used to evaluate the control T1DM. HbAlc shows total average of glycaemia over a period of several months and therefore it is important in evaluating the effectiveness of diabetes treatment and the risk of complications. Increased blood levels of HbAlc warn of possible eye, heart, kidney, and nervous system disorders. 
Table 1. The level of internal consistency of PS scales and subscales

\begin{tabular}{|l|c|}
\hline PS scales and subscales & $\begin{array}{c}\text { Cronbach's } \\
\text { Alpha }\end{array}$ \\
\hline Parenting style questionnaire & 0.74 \\
\hline Authoritative parenting style & 0.83 \\
\hline Connection Dimension (Warmth \& Support) & 0.61 \\
\hline Regulation Dimension (Reasoning/Induction) & 0.78 \\
\hline Autonomy Granting Dimension (Democratic Participation) & 0.66 \\
\hline Authoritative parenting style & 0.84 \\
\hline Physical Coercion Dimension & 0.72 \\
\hline Verbal Hostility Dimension & 0.72 \\
\hline Non-Reasoning/Punitive Dimension & 0.53 \\
\hline Authoritarian parenting style & 0.82 \\
\hline Permissive parenting style & 0.47 \\
\hline
\end{tabular}

Parenting style. The parenting style was assessed by the Parenting styles and dimensions questionnaire (Parenting Styles and Dimensions QuestionnaireShort Form, PSDQ; Robinson, Mandleco, Olsen, Hart, 2001). The questionnaire (Cronbach alpha coefficient - .74) measures authoritative (15 questions Cronbach alpha coefficient - .83), authoritarian (12 questions, Cronbach alpha coefficient -.82 ) and permissive (5 questions, Cronbach alpha coefficient .47) parenting styles. The questionnaire was based on the child's parenting styles according to the model of Baumrind (1971).

I. Authoritative (AUTHORITATIVE PARENTING STYLE):

A. Subfactor 1 - Connection Dimension (Warmth \& Support).

B. Subfactor 2 - Regulation Dimension (Reasoning/Induction).

C. Subfactor 3 - Autonomy Granting Dimension (Democratic Participation).

II. Authoritarian (AUTHORITARIAN PARENTING STYLE):

A. Physical Coercion Dimension.

B. Verbal Hostility Dimension.

C. Non-Reasoning/Punitive Dimension.

III. Permissive (PERMISSIVE PARENTING STYLE):

A. Indulgent Dimension.

Statistical Analysis. Statistical analysis was performed to impute the missing data. In our study, the amount of item-level missing data in the final sample was small (1.1\%) because mean substitution performs adequately when $5 \%$ of data is missing. Means, standard deviations, bivariate correlations, and internal consistency were calculated for all variables. We examined independent variables to determine their appropriateness for multivariate analyses. Two steps analysis was applied. The total sample of mothers $(N=131)$ was investigated during the first stage of the analysis in order to assess the relationship between T1DM management Parenting Style. Cronbach's Alpha was used to evaluate the level of internal consistency reliability in the above presented multi-item scale. Internal consistency was .74 (Table 1).

Logistic regression analysis was applied in order to investigate associations between diabetes management and PS. In the first step, we conducted univariate binary logistic regression (BLR) analysis. Later cluster analysis was applied to the multidimensional analysis of the data.

Ethical Statement. Ethics approval for the study was provided by the Kaunas Regional Biomedical Research Ethics Committee (reference number BE-2-62). Additionally, written informed consent for participation in the questionnaire survey was obtained from mothers of children with T1DM.

\section{RESULTS}

Table 2 and Table 3 describe demographic and socio-economic characteristics of all mothers and their children. The results show that study sample was quite representative, balanced by children gender.

Dividing the glycaemic control results into two groups (sufficient glycaemic control $=<7.0$ and insufficient glycaemic control $>7.1$ ) and 
Table 2. Demographic and social characteristics of the total sample and subsample studied

\begin{tabular}{|c|c|c|}
\hline Independent Variables & $N$ & $\%$ \\
\hline \multicolumn{3}{|c|}{ Total sample studied, $N=131$} \\
\hline \multicolumn{3}{|c|}{ Children's sex } \\
\hline \multicolumn{3}{|c|}{ Total sample studied, $N=131$} \\
\hline Girls & 66 & 51.5 \\
\hline Boys & 65 & 48.5 \\
\hline \multicolumn{3}{|c|}{ Parents' sex } \\
\hline Women & 131 & 100 \\
\hline \multicolumn{3}{|c|}{ Marital status } \\
\hline Married & 111 & 85.1 \\
\hline divorced & 12 & 9.0 \\
\hline Live separately & 1 & .7 \\
\hline Widow & 3 & 2.2 \\
\hline Single mother & 4 & 3.0 \\
\hline \multicolumn{3}{|c|}{ Parental education } \\
\hline Basic/ Less than high school & 3 & 2.2 \\
\hline Secondary/High school & 15 & 11.2 \\
\hline Special secondary & 5 & 3.7 \\
\hline College/College degree & 30 & 22.4 \\
\hline University/Graduate degree & 78 & 60.4 \\
\hline \multicolumn{3}{|c|}{ Financial situation of the family } \\
\hline Very good & 7 & 5.2 \\
\hline Good & 88 & 67.9 \\
\hline Average & 33 & 24.6 \\
\hline Bad & 3 & 2.2 \\
\hline
\end{tabular}

Table 3. Demographic and social characteristics of the total sample and subsample studied

\begin{tabular}{|l|c|c|c|c|c|}
\hline & Mean, $\boldsymbol{S D}$ & Median & Mode & Variance \\
\hline \multicolumn{4}{|c|}{ Total sample studied, N=131 } \\
\hline Parents' age & 37.83 & 37.0 & 37 & 19.13 \\
\hline Number of children in the family & 1.98 & 2.0 & 2 & 0.68 \\
\hline Children's age & 9.26 & 9.0 & 11 & 4.16 \\
\hline Duration of sickness & 3.53 & 3.0 & 1 & 5.92 \\
\hline Glycaemic control & 7.43 & 7.3 & 6.70 & 1.91 \\
\hline
\end{tabular}

comparing PS data in these groups, we did not find statistically significant differences in maternal PS scales (Table 4). Only trends can be observed, that constructive parenting style as authoritative and children's sufficient diabetes management could interact. Meanwhile, insufficient disease control interacts with negative parenting manifestations.

The data presented in Table 5 shows that child diabetes management and maternal PS scales do not have any correlation. 
Table 4. Responses of the respondents about children T1DM management and PS scales and subscales of mothers $(N=131)$

Note. Independent-Samples MannWhitney $U$ Test, $p<.05$.

\begin{tabular}{|c|c|c|c|}
\hline Independent Variables & $\begin{array}{c}\text { Diabetes } \\
\text { management }\end{array}$ & Mean rank & $p$ \\
\hline \multirow{2}{*}{ Authoritative parenting style } & Insufficient & 62.27 & \multirow{2}{*}{.16} \\
\hline & Sufficient & 72.03 & \\
\hline \multirow{2}{*}{$\begin{array}{l}\text { Connection Dimension (Warmth \& } \\
\text { Support) }\end{array}$} & Insufficient & 63.28 & \multirow{2}{*}{.23} \\
\hline & Sufficient & 71.56 & \\
\hline \multirow{2}{*}{$\begin{array}{l}\text { Regulation Dimension (Reasoning/ } \\
\text { Induction) }\end{array}$} & Insufficient & 64.38 & \multirow{2}{*}{.48} \\
\hline & Sufficient & 69.33 & \\
\hline \multirow{2}{*}{$\begin{array}{l}\text { Autonomy Granting Dimension } \\
\text { (Democratic Participation) }\end{array}$} & Insufficient & 61.87 & \multirow{2}{*}{.11} \\
\hline & Sufficient & 72.85 & \\
\hline \multirow{2}{*}{ Authoritarian parenting style } & Insufficient & 68.05 & \multirow{2}{*}{.37} \\
\hline & Sufficient & 61.81 & \\
\hline \multirow{2}{*}{ Physical Coercion Dimension } & Insufficient & 67.2 & \multirow{2}{*}{.57} \\
\hline & Sufficient & 63.53 & \\
\hline \multirow{2}{*}{ Verbal Hostility Dimension } & Insufficient & 68.59 & \multirow{2}{*}{.26} \\
\hline & Sufficient & 60.70 & \\
\hline \multirow{2}{*}{ Non-Reasoning/Punitive Dimension } & Insufficient & 66.82 & \multirow{2}{*}{.72} \\
\hline & Sufficient & 64.33 & \\
\hline \multirow{2}{*}{ Permissive parenting style } & Insufficient & 64.21 & \multirow{2}{*}{.43} \\
\hline & Sufficient & 69.66 & \\
\hline
\end{tabular}

Table 5. Correlation between children T1DM management and PS scales and subscales of mothers $(N=131)$

Notes. Spearman linear correlation coefficient. Correlation is significant at the .05 level (2-tailed).

\begin{tabular}{|l|c|c|}
\hline Independent Variables & Correlation & $p$ \\
\hline Diabetes management & & .54 \\
\hline Authoritative parenting style & -.03 & .72 \\
\hline Connection Dimension (Warmth \& Support) & -.23 & .941 \\
\hline Regulation Dimension (Reasoning/Induction) & .005 & .26 \\
\hline Autonomy Granting Dimension (Democratic Participation) & .06 & .63 \\
\hline Authoritarian parenting style & .02 & .76 \\
\hline Physical Coercion Dimension & .02 & .94 \\
\hline Verbal Hostility Dimension & .004 & .53 \\
\hline Non-Reasoning/Punitive Dimension & .03 & .48 \\
\hline Permissive parenting style & -.043 & \\
\hline
\end{tabular}

A deeper data analysis was performed using binary logistic regression to reveal the interactions between parental PS and T1DM management. Binary logistic regression analysis revealed that mothers' PS (composite index) scales and subscales were not statistically significant predictors of glycaemic control in children with T1DM (Table 6).

Clusteranalysis was applied to multidimensional data analysis, fusing the non-hierarchical $k$-means cluster analysis method. Using cluster analysis, two groups of subjects with different profiles 
Table 6. Children's T1DM management and mothers' PS scales and subscales (total sample, $N=131$ ): results of univariate and multivariate logistic regression

\begin{tabular}{|c|c|c|c|c|}
\hline \multirow[t]{2}{*}{ Predictors } & $\begin{array}{l}\text { Insufficient diabetes } \\
\text { management }\end{array}$ & $\begin{array}{l}\text { Sufficient diabetes } \\
\text { management }\end{array}$ & \multirow{2}{*}{ OR } & \multirow{2}{*}{ CI } \\
\hline & $n(\%)$ & $n(\%)$ & & \\
\hline Diabetes management & 88 & 43 & & \\
\hline \multirow{2}{*}{ Authoritative parenting style } & $57(64.4)$ & $22(51.2)$ & 1 & \multirow{2}{*}{$0.82-3.62$} \\
\hline & $31(35.6)$ & $21(48.8)$ & 1.72 & \\
\hline \multirow{2}{*}{ Connection Dimension (Warmth \& Support) } & $73(83)$ & $30(68.8)$ & 1 & \multirow{2}{*}{$0.89-4.96$} \\
\hline & $15(17)$ & $13(30.2)$ & 2.1 & \\
\hline \multirow{2}{*}{ Regulation Dimension (Reasoning/Induction) } & $53(60.2)$ & $20(46.5)$ & 1 & \multirow{2}{*}{$0.83-3.63$} \\
\hline & $35(39.8)$ & $23(53.5)$ & 1.74 & \\
\hline \multirow{2}{*}{$\begin{array}{l}\text { Autonomy Granting Dimension (Democratic } \\
\text { Participation) }\end{array}$} & $36(41.4)$ & $11(25.6)$ & 1 & \multirow{2}{*}{$0.91-4.60$} \\
\hline & $52(58.6)$ & $32(74.4)$ & 2.05 & \\
\hline \multirow{2}{*}{ Authoritarian parenting style } & $56(63.6)$ & $32(74.4)$ & 1 & \multirow{2}{*}{$0.26-1.35$} \\
\hline & $32(36.4)$ & $11(25.6)$ & 0.6 & \\
\hline \multirow{2}{*}{ Physical Coercion Dimension } & $76(86.4)$ & $39(93)$ & 1 & \multirow{2}{*}{$0.12-1.78$} \\
\hline & $12(13.6)$ & $4(7)$ & 0.47 & \\
\hline \multirow{2}{*}{ Verbal Hostility Dimension } & $37(42)$ & $23(53.5)$ & 1 & \multirow{2}{*}{$0.3-1.31$} \\
\hline & $51(58)$ & $20(46.5)$ & 0.6 & \\
\hline \multirow{2}{*}{ Non-Reasoning/Punitive Dimension } & $65(73.9)$ & $34(79.1)$ & 1 & \multirow{2}{*}{$0.12-1.78$} \\
\hline & $23(26.1)$ & $9(20.9)$ & & \\
\hline \multirow{2}{*}{ Permissive parenting style } & $15(17)$ & $2(4.7)$ & 1 & \multirow{2}{*}{$0.91-19.34$} \\
\hline & $73(83)$ & $41(95.3)$ & 4.21 & \\
\hline
\end{tabular}

Notes. Significant relationships are provided in bold. OR - Odds Ratio; 95\% CI - 95\% Confidence Interval.

Figure. Mothers' PS subscales' cluster analysis

Notes. 1. Connection Dimension (Warmth \& Support). 2. Regulation Dimension (Reasoning/Induction). 3. Autonomy Granting Dimension (Democratic Participation). 4. Permissive parenting style. 5. NonReasoning/Punitive Dimension. 6. Physical Coercion Dimension. 7.Verbal Hostility Dimension.

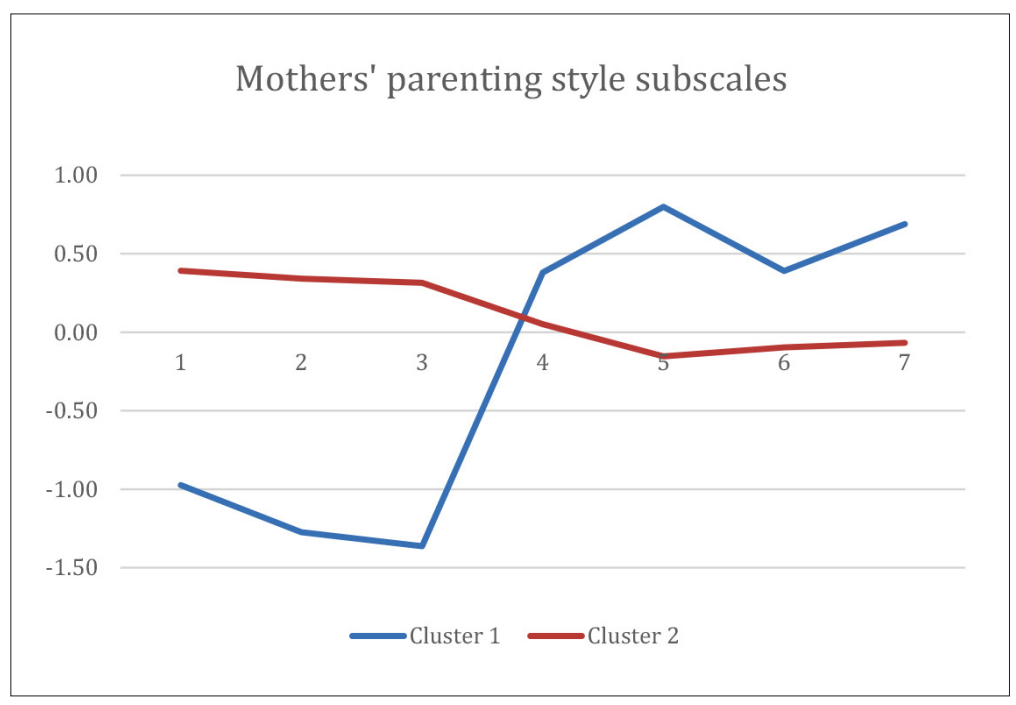


and different PS expression were distinguished. For convenience, the scales are presented on a standardized Z scale.

Figure shows that the largest group of respondents $(81.5 \%)$ tended to use elements of negative parenting style - permissive parenting dimension, nonreasoning/punitive dimension, physical coercion dimension, verbal hostility dimension (1 cluster/blue line). In communication with children, they lacked emotional warmth, support, reasoning and especially democratic participation. The second group of subjects $(18.5 \%)$ consisted of mothers who tended to use positive parenting elements. Meanwhile, they had no big difference in negative parenting style elements (2 cluster/orange line).

\section{DISCUSSION}

In this study we focused on some social, family, and parenting determinants of children's T1DM management. We placed the main emphasis in our analysis on the parenting style as the important factor determining children with T1DM management. As we know, parenting style could play an important role in development of children's health and heath behaviour. We aimed to investigate the association between children's T1DM management and mothers' PS, which constitute an important component in the management of children chronical disease.

The results of much research show the importance of parenting style for children's T1DM management: collaborative parenting was significantly related to lower HbAlc (Gruhn et al., 2016). A significant relationship was found between authoritative mothering and adolescent self-care behaviours and metabolic control (Greene et al., 2010). Meanwhile, our study results show that maternal parenting style does not interact with child's disease control. These results are not exceptional and contradictory. Monaghan and colleagues suggest that although parenting style does not interact with disease control, an authoritative parenting style may contribute to greater age-appropriate child's behavioural adherence (Monaghan et al., 2012). Miller-Johnson and colleagues' study results showed the parentchild conflict, adherence and metabolic control correlation (Miller-Johnson et al., 1994). Shorer and colleagues' research results showed fathers' parenting style influence on their children's
T1DM management. Higher authoritativeness of fathers, but not mothers, was associated with better treatment adherence and improved glycaemic control (Shorer et al., 2011). Authoritative fathering is especially important in adolescence: Greene and colleagues found positive correlation with the selfcare behaviors of blood glucose monitoring, taking insulin and not skipping meals (Greene et al., 2010).

Strengths and limitations. The strength of this study is an attempt to understand the influence of parenting style on child's T1DM management. This study is based on a biopsychosocial approach. Managing a child's illness is a process where parents are primarily involved. Parents need not only to manage their children's T1DM, but also to train certain patterns of health behaviour in their children that help to avoid complications. Parenting style plays an important role in this process. One of limitations in this study is no involvement of other factors. It is important to include such independent variables as children adherence, self-care behaviour, parents - children's relationship peculiarities in this type of research.

\section{CONCLUSIONS}

Parenting style is important not only for the child's personality formation but also for mental and physical health. How parents raise children with chronic diseases is of paramount importance, whereas the child and parents have to deal with the day-today challenges of disease management. While study results do not show management correlation with mothers' PS scales and subscales, cluster analysis demonstrated domination of negative mothers' PS elements: lack of emotional warmth, support, reasoning and especially democratic participation.

Acknowledgments. This study was funded by the Lithuanian Ministry of Social Security and Labour. We would like to express our gratitude for help to psychologists who voluntarily assisted in conducting the survey. Particularly, we are grateful to mothers of children with T1DM who agreed to participate in this survey and who sincerely and with devotion filled in the questionnaire forms. The results of the study showed mothers' parenting difficulties in relation to children's T1DM management. Mothers of children with T1DM face tremendous challenges daily while parenting and managing their offspring's T1DM. 


\section{REFERENCES}

Anderson, B., Ho, J., Brackett, J., Finkelstein, D., \& Laffel, L. (1997). Parental involvement in diabetes management tasks: Relationships to blood glucose monitoring adherence and glycemic control in young adolescents with insulin-dependent diabetes mellitus. Journal of Pediatrics, 130, 257-265. https://doi. org/10.1016/S0022-3476(97)70352-4

Armstrong, B., Mackey, E. R., \& Streisand, R. (2011). Parenting behavior, child functioning, and health behaviors in preadolescents with type 1 diabetes. Journal of Pediatric Psychology, 36, 1052-1061. https:// doi.org/10.1093/jpepsy/jsr039

Baumrind, D. (1971). Current patterns of parental authority. Developmental Psychology, 4, 1-103. https:// psycnet.apa.org/doi/10.1037/h0030372

Butler, J. M., Berg, C. A., King, P., Gelfand, D., Fortenberry, K., Foster, C., \& Wiebe, D. (2009). Parental negative affect and adolescent efficacy for diabetes management. Journal of Family Psychology, 23, 611614. https://psycnet.apa.org/doi/10.1037/a0016141

Cameron, F. J., Skinner, T. C., de Beaufort, C. E., Hoey, H., Swift, P. G., Aanstoot, H., \& Skovlund, S. E. (2008). Are family factors universally related to metabolic outcomes in adolescents with Type 1 diabetes. Diabetic Medicine, 25, 463-468. https://doi.org/10.1111/j.14645491.2008.02399.x

Cefalu, T., \& Ratner, R. (2014). The diabetes control and complications trial/epidemiology of diabetes interventions and complications study at 30 years: The "Gift" that keeps on giving! Diabetes care, 37, 5-7. doi: $10.2337 / \mathrm{dc} 13-2369$.

Centers for Disease Control and Prevention. (2018). National diabetes fact sheet: National estimates and general information on diabetes and prediabetes in the United States, Atlanta, GA: U.S. Department of Health and Human Services, Centers for Disease Control and Prevention.

Codner, E., Acerini, C. L., Craig, M. E., Hofer, S. E., \& Maahs, D. M. (2018). ISPAD Clinical Practice Consensus Guidelines 2018: What is new in diabetes care? Pediatric diabetes, 19(27), 5-6. https://doi. org/10.1111/pedi.12759

Drew, L. M., Berg, C., \& Wiebe, D. J. (2010). The mediating role of extreme peer orientation in the relationships between adolescent-parent relationship and diabetes management. Journal of Family Psychology, 24(3), 299-306. https://doi.org/10.1037/a0019352

Duncan, L. G., Coatsworth, J. D., \& Greenberg, M. T. (2009). A model of mindful parenting: Implications for parent - child relationships and prevention research. Clinical Child and Family Psychology Review, 12, 255270. https://doi.org/10.1007/s10567-009-0046-3

Gruhn, M. A., Lord, J. H., \& Jaser, S. S. (2016). Collaborative and overinvolved parenting differentially predict outcomes in adolescents with type 1 diabetes.
Health Psychology, 35(7), 652-660. https://psycnet.apa. org/doi/10.1037/hea0000349

Ivey, J. B., Wright, A., \& Dashiff, C. J. (2009). Finding the balance: Adolescents with type 1 diabetes and their parents. Journal of Pediatric Health Care, 23, 10-18. https://doi.org/10.1016/j.pedhc.2007.12.008

Jaser, S. S., \& Grey, M. (2010). A pilot study of observed parenting and adjustment in adolescents with type 1 diabetes and their mothers. Journal of Pediatric Psychology, 34(7), 738-747. https://doi.org/10.1093/ jpepsy/jsp098

Landers, S. E., Friedrich, E. A., Jawad, A. F., \& Miller, V. A. (2016). Examining the interaction of parental involvement and parenting style in predicting adherence in youth with type 1 diabetes. Families, Systems, \& Health, 34(1), 41-50. https://psycnet.apa. org/doi/10.1037/fsh0000183

Lewin, A. B., Heidgerken, A. D., Geffken, G. R., Williams, L. B., Storch, E. A., Gelfand, K. M., \& Silverstein, J. H. (2006). The relation between family factors and metabolic control: The role of diabetes adherence. Journal of Pediatric Psychology, 31(2), 174183. https://doi.org/10.1093/jpepsy/jsj004

Martin, C. L., Albers, J. W., Pop-Busui, R., \& DCCT/ EDIC Research Group. (2014). Neuropathy and related findings in the diabetes control and complications trial/epidemiology of diabetes interventions and complications study. Diabetes Care, 37(1), 31-38. https://doi.org/10.2337/dc13-2114

McKee, L., Roland, E., Coffelt, N., Olson, A. L., Forehand, R., Massari, C., ... Zens, M. S. (2007). Harsh discipline and child problem behaviors: The roles of positive parenting and gender. Journal of Family Violence, 22, 187-196. https://doi.org/10.1007/s10896007-9070-6

Miller-Johnson, S., Emery, R. E., Marvin, R. S., Clarke, W., Lovinger, R., \& Martin, M. (1994). Parentchild relationships and the management of insulindependent diabetes mellitus. Journal of Consulting and Clinical Psychology, 62(3), 603-610.

Monaghan, M., Horn, I. B., Alvarez, V., Cogen, F. R., \& Streisand, R. (2012). Authoritative parenting, parenting stress, and self-care in pre-adolescents with type 1 diabetes. Journal of Clinical Psychology in Medical Settings, 19(3), 255-261. doi: 10.1007/s10880-011-9284-x.

Nathan, D. M., \& DCCT/EDIC Research Group (2014). The diabetes control and complications trial/ epidemiology of diabetes interventions and complications study at 30 years: Overview. Diabetes care, 37(1), 9-16. https://doi.org/10.2337/dc13-2112

Palmer, D. L., Osborn, P., King, P. S., Berg, C., Butler, L., Butner, J., ... Wiebe, D. J. (2011). The structure of parental involvement and relations to disease management for youth with type 1 diabetes. Journal of Pediatric Psychology, 36, 596-605. doi: 10.1093/jpepsy/jsq019 
Serkel-Schrama, I. J., de Vries, J., Nieuwesteeg, A. M., Pouwer, F., Nyklíček, I., Speight, J., ... \& Hartman, E. E. (2016). The association of mindful parenting with glycemic control and quality of life in adolescents with type 1 diabetes: Results from Diabetes MILES - The Netherlands. Mindfulness, 7(5), 1227-1237. https://doi. org/10.1007/s12671-016-0565-1

Shorer, M., David, R., Schoenberg-Taz, M., LevaviLavi, I., Phillip, M., \& Meyerovitch, J. (2011). Role of parenting style in achieving metabolic control in adolescents with type 1 diabetes. Diabetes Care, 34(8), 1735-1737. https://doi.org/10.2337/dc10-1602

Silverstein, J., Klingensmith, G., Copeland, K., Plotnick, L., Kaufman, F., Laffel, L., \& Clark, N. (2005). Care of children and adolescents with type 1 diabetes: A statement of the American Diabetes Association. Diabetes Care, 28, 186-212. https://doi.org/10.2337/ diacare.28.1.186

Stoker Greene, M., Mandleco, B., Olsen Roper, S., Marshall, E. S., \& Dyches, T. (2010). Metabolic control, self-care behaviors, and parenting in adolescents with type 1 diabetes. The Diabetes Educator, 36(2), 326-336. https://doi.org/10.1177/0145721710361270

Turpyn, C. C., \& Chaplin, T. M. (2015). Mindful parenting and parents' emotion expression: Effects on adolescent risk behaviors. Mindfulness, 7, 246-254. https://doi.org/10.1007/s12671-015-0440-5

Umanath, K., \& Lewis, J. B. (2018). Update on diabetic nephropathy: Core Curriculum 2018. American Journal of Kidney Diseases, 71(6), 884-895. https://doi.org/ 10.1053/j.ajkd.2017.10.026

van der Oord, S., Bögels, S. M., \& Peijnenburg, D. (2012). The effectiveness of mindfulness training for children with ADHD and mindful parenting for their parents. Journal of Child and Family Studies, 21, 139147. doi: 10.1007/s10826-011-9457-0

Wherrett, D. K., Ho, J., Huot, C., Legault, L., Nakhla, M., \& Rosolowsky, E. (2018). Type 1 diabetes in children and adolescents. Canadian Journal of Diabetes, 42, S234-S246. https://doi.org/10.1016/j.jcjd.2017.10.036 